\section{Quando a democracia é o estado de natureza}

Wanderley Guilherme dos SANTOS. Governabilidade e democracia natural. Rio de Janeiro, Editora da FGV, 2007. 166 páginas.

\section{Antonio Octávio Cintra}

Governabilidade e democracia natural é o livro mais recente de Wanderley Guilherme dos Santos. Desde já, assinalemos não se tratar de leitura amena. Conquanto escrito com o habitual domínio do idioma e elegância de expressão do autor, constitui um denso e rigoroso arrazoado sobre questões centrais na análise da democracia, preocupações constantes de sua já extensa obra de acadêmico e publicista. É obra para estudo e reflexão, que instiga permanentemente o leitor.

Fiel a uma de suas mais conhecidas características, Santos mantém, ao longo da exposição, uma atitude fortemente crítica em relação a teses por muito tempo tidas como consensuais, algumas delas sobre a política brasileira e outras de alcance mais amplo na moderna ciência política.

Bem demonstrativo de sua atitude de dúvida sistemática é o primeiro capítulo, intitulado "Ensaio sobre o mundo 2005: sugestões historiográficas à análise contemporânea”. Poderia ser uma peça autônoma, pois, enquanto os dois outros capítulos da obra centram-se na mecânica interna da democracia, neste erudito ensaio se esboça o painel da ecologia global do regime democrático, examinado à luz das pesquisas comparativas dos últimos sessenta anos e visto como parte do sistema internacional em evolução.

O autor recapitula toda uma linha de especulação teórica e investigação empírica que trata das relações entre os regimes e as condições socioeconômicas. O texto pioneiro que se propôs destrinçar essas relações foi o de Seymour Martin Lipset. No artigo famoso, aquele autor quis fundamentar as conclusões, não no exame de dois ou três casos, senão na comparação estatística de muitos casos. Contudo, como lembra Santos, sua base de dados se revelou modesta, o lapso temporal que usou, muito curto, e suas conclusões, por exemplo, sobre a solidez democrática do
Chile e do Uruguai de então (anos de 1950) deixaram a nu a insuficiência do enfoque. ${ }^{1}$

Os cinco decênios transcorridos desde a publicação do trabalho lipsetiano mostraram só ocorrer a tradicional e hipotética tensão entre democracia e desigualdades econômicas em situações-limite, nas quais "a pobreza vira miséria, miséria se converte em fome endêmica e, esta, em inevitável mortandade”. Mas, nesse caso, pondera Santos, "a polarização vale igualmente para o par contrário - desigualdades econômicas e ditaduras -, pois, mantendo-se a miséria, as ditaduras se desgastam e terminam por dar lugar a democracias ou a um rodízio de ditaduras" (p. 16). Em suma, as amostras para as comparações têm de ser mais amplas e, dada a específica temporalidade dos fenômenos de consolidação, sobrevivência ou debacle de regimes, os lapsos dos estudos precisam ser muito mais longos do que meros dez ou vinte anos, sob o risco de previsões insubsistentes.

A discussão permite a Santos denunciar o sério problema de recomendações e terapias se escorarem em diagnósticos precários, prática de que são useiras e vezeiras, entre outros, as influentes agências multilaterais.

A seu ver, as teorias sobre o mundo em transformação revelam-se frágeis. Parece existir, nesse tocante, uma cegueira teórica que impede ver as pulsões opostas no contexto internacional, com forças que levam à integração, mas, também, à cissiparidade, geradora de pequenas nações inviáveis. Alerta Santos, então, para o "delicado o problema de compatibilizar uma ordem internacional democrática, representada em parlamentos internacionais constituídos, em princípio, conforme a norma da igualdade jurídica e política, com a minúscula importância material da maioria dos membros desses mesmos parlamentos" (p. 33).

Outra tendência é a da multiplicação de autocracias. Nas chamadas BRICs, exceto o Brasil, há conflitos inocultáveis pela pressão de suas subunidades constitutivas, os quais podem levar a desfechos ditatoriais.

E as perspectivas do Brasil nesse ambiente? Para Santos, falta-nos um projeto autônomo de inserção internacional, "um projeto para levantar, andar e fazer". E conclui nada existir, na lógica democrática, que impeça a redenção econômica 
nacional. As instituições do país revelar-se-iam operacionalmente capazes de evitar a catástrofe da ingovernabilidade ou, pelo menos, daquela que é creditada ao sistema representativo. Essa breve observação, no final do capítulo, merecerá análise detida na continuação do livro, na qual Santos mostra toda a sua discordância com os diagnósticos negativos de nosso sistema político.

Nos dois capítulos posteriores da obra, o autor enfrenta precisamente alguns dos pontos em que diverge das visões pessimistas sobre a política brasileira, em especial as que condenam o funcionamento do sistema representativo no país.

No primeiro deles, "A fenomenologia da competição democrática”, Santos concentra-se no momento eleitoral do funcionamento democrático. Vê o regime sob a mesma óptica de Robert Dahl, ou seja, como resultante de uma progressão dos sistemas políticos ao longo de dois eixos, o da crescente competição política e o da ampliada participação. Esse percurso leva, das autocracias e oligarquias, ao que, para Dahl, são as aproximações empíricas do regime democrático - as chamadas poliarquias.

Para Santos, "o mega-eleitorado brasileiro explodiu os diques da competição confinada, o que significa mais opções de escolha para o eleitor, que só deixa de se beneficiar disso por via do artefato compressor do distritalismo majoritário, caso venha a ser implantado. Mesmo com índice e métrica tão severos como os aqui utilizados, fica provado que, sem manufatura institucional, o oligopólio elitista não se sustentará com facilidade" (p. 56). Para ele, houve no país uma grande transformação cívica, que se traduz em fatos como, por exemplo, a partir de 1994, todas as regiões brasileiras já haverem incorporado mais de 50\% da população à disputa eleitoral. No que ele caracteriza como um extraordinário processo de conversão, inundou-se o mercado de votos e se tornou impossível a continuidade oligárquica, "mantido o sistema proporcional, pela redução da oferta de competição: são muitos os partidos, grande o potencial competitivo, elevadas as chances de vitória" (p. 57).

O foco, no capítulo, é precisamente a presença da competição no sistema político, a qual, quanto mais restrita, tanto mais oligárquico faz o regime. Santos encara o problema da competitivi- dade sistêmica por um ângulo peculiar, com implicações interpretativas, mas também de ordem operacional, pois levam a uma métrica específica da competitividade. Para ele, esta se manifestaria pela oferta maior de candidatos aos postos eletivos. Faltaria, a Dahl e outros, considerarem que possa existir extensa participação dos eleitores, com a competição institucionalizada e a aceitação dos resultados, porém com o número de participantes da disputa sendo reduzido por intermédio de regras previamente acordadas. Em suas palavras, "os sistemas representativos oligárquicos contemporâneos se caracterizam justamente menos por oporem obstáculos à participação política, tal como os regimes aristocráticos e autoritários o faziam ou fazem, do que por criarem dificuldades para a conversão de cidadãos-representados em cidadãos representantes, isto é, por estreitarem o leque de escolhas do eleitorado reprimindo a oferta de candidatos" (p. 41). A esse resultado pode-se chegar mediante "acordos restritivos" entre os próprios adversários.

Quando explica o teor desses acordos restritivos, o autor parece estar questionando os próprios fundamentos da democracia representativa ou, pelo menos, mostrando-lhe as limitações oligárquicas, ao lembrar que, entre as barreiras que nela se erigem, fruto de acordos, inscreve-se, por exemplo, a exigência de o candidato a candidato ser filiado a partido. Piores ainda lhe parecem as coisas quando se delega aos partidos "ordenar, em sistema de listas fechadas, os candidatos preferenciais do partido" (p. 41).

Outra restrição efetiva ocorre, segundo ele, pela apresentação, à escolha do eleitor, de candidatos de "rala diferença quanto à inclinação ideológica, aos atributos pessoais, ou a ambos" (p. 42). Neste caso, é oportuno perguntar se os candidatos deixariam de se diferenciar não por algum mal-intencionado acordo oligárquico, senão, precisamente, para atenderem às preferências do eleitorado. Se tais preferências se concentram no meio do espectro ideológico, conforme um dos famosos modelos explorados por Anthony Downs, em An economic theory of democracy, os candidatos podem ser ideologicamente similares e, não obstante, a competição entre eles ser acirrada, pois apenas um vai ganhar a disputa.

Antes de examinarmos a interpretação que o 
autor faz da competitividade política, vejamos como ele a trata empiricamente. Como de hábito em seu trabalho acadêmico, Santos não teme o dado empírico. No presente caso, a busca de dados requereu esforço e persistência ao longo de vários anos, em que ele e sua equipe dedicaram-se à coleta e à depuração de informações, antes dispersas, boa parte quase perdida, sobre os resultados eleitorais de 1945 a 2006, tanto para a Câmara dos Deputados como para as assembléias legislativas, assim construindo um valioso acervo de dados políticos.

Para o presente propósito, Santos examina a evolução da competitividade partidário-eleitoral, conceito que ele operacionaliza mediante um índice em cujo denominador se registra o número de lugares em disputa num determinado pleito e circunscrição, e no numerador, o dobro do total de candidatos a esses lugares. A medida, normalizada, permite ordenar as eleições pelo seu grau de competição assim definida.

Os dados relativos à totalidade das eleições no período mencionado mostram sensíveis variações temporais e regionais no índice. Por exemplo, quando se calculam as razões entre eleições competitivas e não competitivas, nos pleitos para a Câmara dos Deputados, ao longo de todo o período, são nítidos, por exemplo, os contrastes entre o Sudeste, com uma razão de 1,9, e o Nordeste, em que essa razão é de apenas 0,7 .

Que o autor encontrou relações merecedoras de explicação, não há dúvida. As séries que apresenta, mostrando o crescimento da relação candidatos/vagas ao longo do tempo, e os contrastes regionais, como o acima focado, sugerem algo. Pode-se pensar que o número de candidatos por vaga na verdade seja um proxy da multiplicação partidária. Nas regiões mais atrasadas, quando há disputa política, ela se dá entre frações da elite, em geral expressando-se por meio de dois partidos - como eram, em muitas localidades, na República de 46, a UDN e o PSD -, conforme mostram inúmeros estudos de caso da política local. A diversificação de interesses, com a urbanização e a industrialização, sobretudo, e a ampliação de participação levariam ao aparecimento de mais partidos e, portanto, a maior oferta de candidatos. Para esse fenômeno chamava a atenção, alguns decênios atrás, um dos pioneiros dos estudos eleitorais entre nós, Orlando de Carvalho. ${ }^{2}$ Como interpretar tais fatos em termos de competitividade?

Santos parece encarar o mercado político como similar ao mercado econômico da competição perfeita. Assim, numa eleição, a pletora de candidatos se assemelharia a uma oferta atomizada de bens divisíveis, oferecidos por inúmeros competidores, dando ao eleitor amplas oportunidades de escolha.

Examinemos o assunto mais de perto. No mercado político, o pressuposto é o de o eleitor buscar o poder político, ou seja, a capacidade de influenciar o curso das políticas públicas a seu favor. Quão divisível é esse bem? Mesmo nos sistemas que mais extremam a lógica consociativa, tipificada por Lijphart, construindo suas instituições com pesos e contrapesos, separação de poderes, federalismo, sistema eleitoral proporcional, multipartidarismo, mesmo aí, o poder exige sempre alta agregação. Seu fracionamento tem limites claros, sob pena de paralisia decisória e ineficácia.

Tomemos, então, a hipótese de um número bastante grande de candidatos, não filiados a partidos, eleitos como candidatos avulsos, assim se contornando a restrição que Santos aponta de terem os partidos o monopólio da apresentação de candidatos. Possivelmente se elevará, sobremodo, a relação candidatos/postos, numa eleição bem próxima da competição atomizada. Qual o significado desse fato? Descobririam os eleitos ser necessário agruparem-se de acordo com as preferências compartilhadas com outros, para ter um mínimo de eficácia nas deliberações, em geral redutíveis a opções duais. Teríamos, logo, protopartidos e, possivelmente, verdadeiros partidos dentro de pouco tempo. Bem poderiam estes já se haver constituído na fase eleitoral, pois, para o eleitor, o significado das eleições em termos de poder a conquistar seria mais claro.

No plano eleitoral, vencido certo limiar, é ilusório que mais candidatos signifiquem maior possibilidade de escolhas significativas. Por um lado, há claros limites cognitivos para o eleitor, uma óbvia necessidade de simplificar a escolha, eventualmente até reduzindo-a a uma opção entre A e B. Ademais, o espectro de opções significativas que uma avalanche de candidatos propicia é reduzido e, mesmo que não, o candidato eleito 
terá a sua eficácia condicionada ao apoio de outros. A maneira de lograr esse apoio é no seio de um partido e, quase sempre, de uma coalizão parlamentar. Vai-se requerer, na hipótese de motivações ideológicas ou programáticas, o encontro de denominadores comuns, que vão por certo obliterar as nuanças que o candidato singular pode ter oferecido ao eleitor na campanha, para diferenciar-se dos demais.

Por outra parte, serão eleições com escolhas entre duas opções necessariamente pouco competitivas? Nem sempre. Um critério importante para uma eleição ser competitiva é o quão incertos sejam os resultados, ao longo de uma seqüência de eleições. As eleições parlamentares, nos sistemas majoritários/distritais, podem ser bastante competitivas. É bem verdade haver muitos safe districts, por exemplo, nos Estados Unidos e na Inglaterra, poliarquias que adotam o sistema majoritário, de maioria relativa, em distritos uninominais. Mas, vistos os resultados em sua expressão nacional, as eleições parlamentares permitem, nesses países, os revezamentos de maiorias, que podem implicar mudanças de políticas, um claro indicador de competitividade sistêmica.

Talvez seja mais útil pensar na eleição com opção dual como sendo não competitiva quando ela se dá em contextos tradicionais, como parecem revelar os próprios dados de Santos, acima mencionados, relativos, por exemplo, ao Nordeste. Nesses casos, restringe-se a competição mediante a retirada, da disputa eleitoral, de interesses relevantes. Nos regimes de participação limitada, pode dar-se a competição, até acirrada, entre frações da elite, deixando, contudo, de fora, os interesses de amplos setores da população, privados do voto.

Uma observação final diz respeito ao índice proposto por Santos. Suponhamos uma situação de muitos candidatos, apresentados por vários partidos, mas com um dos partidos conquistando, numa seqüência de eleições, uma altíssima percentagem dos votos, digamos 90\%, ficando os demais com apenas 10\%. A nosso ver, independentemente de o número de candidatos poder ser bastante alto em relação ao número de posições em disputa, trata-se de uma eleição pouco competitiva. O índice proposto não nos parece sensível a este aspecto.
Em suma, tem razão Santos em mostrar que passamos de um regime oligárquico a um poliárquico e em centrar sua análise no aumento da competitividade no sistema político, ainda que nos suscite dúvidas a sua concepção deste último fenômeno e, portanto, a sua forma de medi-lo.

Constitui a poliarquia adquirida, marcada pela disputa por lugares de poder, estádio irreversível? O capítulo conclui com uma nota de cautela, ao dizer que "nada assegura [...] que o exercício do poder não venha a produzir estados críticos que antecedem a disrupção. Há limites também para a virtū" (p. 64).

No alentado capítulo 3, Santos passa a uma outra etapa, aquela em que a representação, formada no momento anterior, passa a desempenhar-se no parlamento. Nessa fase, ganha relevo a questão da governabilidade parlamentar. O autor retoma sua velha discordância com os diagnósticos que embasam as propostas de "reforma política", sobretudo as que visam a restrições na operação do sistema eleitoral proporcional ou, até mesmo, à sua substituição, pois para ele não é do funcionamento das regras eleitorais que virão os "estados críticos que antecedem à disrupção ainda possível".

Antes de dirigir o foco para o caso brasileiro, Santos retoma algumas preocupações do capítulo inicial, e faz observações sobre a evolução dos sistemas políticos no plano mundial, desde 1950, contudo relevantes para pôr nossos problemas em contexto. Para ele, as dificuldades relativas à capacidade governativa provêm, hoje, da disseminação e não do esgotamento da ordem democrática: "Precisamente porque não se conheciam as conseqüências do funcionamento rotineiro de reais democracias, suas condições normais de operação costumam provocar apreensões, confundindo-se a normalidade funcional com sintomas de patologias" (p. 77). Contraposto ao "estado de natureza" dos contratualistas, cujo referente empírico eram as ordens autocráticas, o novo estado de natureza, em sua visão, é o das instituições representativas, as quais, ao se tornarem democráticas, em ambiente oligárquico, levam a uma suposta "crise de governabilidade", sobretudo no plano parlamentar. Em tal conjuntura, o "problema real e naturalmente democrático" de reconciliar conflitos e garantir a cooperação 
produtiva entre milhões de seres humanos isonômicos (iguais perante a lei) converte-se em "suposta patologia”. Assim, enquanto as instituições democráticas não forem o estado de natureza, os efeitos de operação de uma democracia ordinária serão vistos como indicadores de estados críticos.

Ora, dado o seu papel na formação do parlamento, o sistema eleitoral torna-se forte candidato a vilão da peça. Quanto a esse veredicto, Santos tem sido, de longa data, reconhecidamente enfático em contestar que, entre as condições suficientes de ingovernabilidade, se encontram os sistemas eleitorais. Sobretudo quando percebe, no diagnóstico, a intenção condenatória do sistema proporcional, que se co-responsabilizou "pela fantástica mobilização dos microconglomerados da comunidade nacional, fazendo-os ingressar na sociedade política" (p. 78). Na atual fase de conhecimentos, observa, não se prova que a fórmula bipartidária otimize um governo representativo inteligente (mas ele próprio adverte que tampouco se prova que do multipartidarismo resulte sempre em governo representativo inteligente).

$\mathrm{Na}$ verdade, numerosas teses sobre os sistemas de governo democráticos e a sua operação, antes tidas como certezas, estão hoje sob escrutínio. Um tópico, por exemplo, sob reavaliação, é o do multipartidarismo e seus presumidos efeitos desestabilizadores. Os estudos sobre os governos de coalizão em democracias mais consolidadas do continente europeu têm permitido uma visão mais equilibrada sobre a multiplicidade partidária. Santos, por sua parte, arrosta a visão negativa do multipartidarismo nacional.

Da mesma forma como nega a importância causal dos sistemas eleitorais, também rejeita serem o número de partidos e os graus de fracionamento do sistema partidário relevantes para entender crises de governabilidade parlamentar. Para ele, a interrogação sobre qual o número ótimo de partidos é imprópria, pois a otimização de um governo representativo inteligente independe do número de partidos. Lembra com razão que um sistema de dois partidos, se polarizados, pode ser ruim.

Para associar os sistemas eleitorais com a otimização do que chama "governos inteligentes", insiste ser necessário examinar sistemas operantes no longo prazo, ter instrumentos de medida do conceito "capacidade governativa" e também estipular precisamente a extensão de significado da proliferação partidária parlamentar. Para ele, nesse rol, só se progrediu quanto ao último aspecto, a partir do clássico trabalho de Douglas Rae, introdutor do conhecido índice F de fracionamento partidário. Mas a leitura dessa medida tem de se ater ao que seu cálculo produz. Ou seja, é uma medida de qual a probabilidade, no agregado, de dois parlamentares, selecionados aleatoriamente, pertencerem ou não ao mesmo partido.

Contudo, Santos chama a atenção para um problema habitualmente ignorado no cálculo de F, a saber, a partir de que tamanho percentual um partido entra ou deixa de entrar nesse cálculo. O ponto de corte é uma decisão necessária ao cálculo, mas, ao medir um fenômeno político, não se pode ignorar a questão substantiva. Na observação do autor, "a reverberação política desses níveis de computação depende da intensidade da competição parlamentar, tal como estimada pela diferença entre situação e oposição. [...] Ainda quando a supremacia da 'situação' aparece esmagadora, convém examinar quais os partidos descartados e o que representam parlamentar e eleitoralmente" (p. 117).

Sendo inevitáveis indagações substantivas ao se calcular o índice F, ganham elas nova urgência quando se tenciona, com base nos diagnósticos sobre a funcionalidade parlamentar, fixar "cláusulas de barreira". Para o autor, não havendo representação parlamentar, as ruas se convertem em "mercados imprevisíveis e incontroláveis". A esse propósito, cita Powell Jr.: "easy entry into the legitimate decision-making arenas tend to dampen turmoil in the streets" (p. 120).

Turmoil é, sim, um dos desfechos possíveis. Observa-se, porém, que, como em todas as esferas da atividade humana, também na política se fazem tradeoffs. Em países com altas barreiras, como a Alemanha, seja ou não justificado o tradeoff para cuja solução se optou pelo elevado limiar da Sperrklause, o eleitorado aprendeu que, mais além do simbolismo de votar em agremiações minúsculas, devia, para tornar seu voto eficaz, concentrá-lo num partido eleitoralmente viável, mais próximo ideologicamente de sua opção primeira. ${ }^{3}$ Como resultado, com duas ou três elei- 
ções, o número de votos privados de acesso ao parlamento diminuiu drasticamente. ${ }^{4}$ Diante desse fato, não tem o mesmo vigor a afirmativa de Santos de que "cláusulas de barreira não são mecanismos para prevenir excessos de fracionalização, mas mecanismos para reduzir a competição e a representação político-partidárias" (p. 109). Se tal ocorre, tende a se dar na margem, na medida em que as eleições se sucedem.

Cabe-lhe total razão, todavia, quando acentua serem necessariamente indispensáveis a modelos explicativos de instabilidade parlamentar o peso relativo dos partidos, a distância ideológica entre eles e a intensidade de suas preferências. É quanto ao peso relativo dos partidos, segundo ele, que a controvérsia sobre o número de partidos ganha relevância. Da distância ideológica entre os partidos e do peso relativo destes é que dependem as probabilidades de coalizões governativas e o papel que as agremiações nelas desempenham. Essas especificações, Santos as recupera de Sartori, autor para quem importa o potencial de coalizões implícito em todo parlamento e a redução desse potencial a conjunto administrável de possibilidades, redução operada pelos critérios da distância e do peso relativo das siglas. ${ }^{5}$

Santos faz bem em alertar para quão apressado seja simplesmente tentar fixar um número de partidos além do qual o parlamento seria inadministrável e ingovernável. No entanto, sua própria exposição, ao mostrar a importância das pequenas siglas parlamentares, eventualmente ignoradas nos cálculos de $\mathrm{F}$ ou do índice $\mathrm{N}$, dele derivado ("número efetivo de partidos"), ${ }^{6}$ deixa entrever um problema, que é o mesmo contra o qual invectivam os proponentes de reformas políticas: dados os diversos quóruns necessários às deliberações das matérias, sobretudo quando a diferença numérica entre governo e oposição for mínima, podem os pequenos partidos tornar-se "pivotais" e extrair preço desproporcional a seu peso eleitoral para ajudar na formação da maioria. Uma instância muito interessante é apresentada, por exemplo, no excelente estudo de caso que Santos faz, em seção deste capítulo, da votação em primeiro turno da emenda da reeleição, em 1997. Em geral, verificase não haver paralisia de decisão, mas o destravamento do processo parlamentar tem alto custo para a legitimidade da instituição.
O tema do sistema partidário, visto como bi ou pluripartidário, ganha importância na literatura pelas hipóteses que ligam essas configurações à estabilidade, à governabilidade e à eficácia do sistema de governo. Para Santos, seja qual for o número de partidos parlamentarmente representados e significativos nas coalizões, não há ameaça à governabilidade. Essa ameaça surge na presença de duas condições: cessar a vantagem numérica de cadeiras da situação sobre a oposição e os grupos que compõem as coalizões passarem a considerar, ao se radicalizarem, que os custos de sair de qualquer coalizão virtual majoritária sejam inferiores aos custos de participar dela. Em termos do modelo formal a que recorre, a situação implica a redução do segmento de possíveis trade offs. Nessa hipótese, um razoável poder parlamentar se junta à disposição para a não-negociação.

Santos trata tal hipótese valendo-se de seu próprio conceito de equilíbrio, diverso do corrente em muito da literatura. Os familiarizados com seu opus magnum, O cálculo do conflito, ${ }^{7}$ reconhecerão, nesse ponto, a recuperação de um tema central nas preocupações do autor, aqui tratado à luz de novos dados. Para ele, analogamente ao conceito físico de "forças", trata-se da presença de capacidades iguais de produzir efeitos e, por isso mesmo, quando em antagonismo, a anulação mútua de forças. Daí, um parlamento equilibrado ser aquele "no qual existem as condições estruturais para a não-produção de efeitos, o imobilismo, caso os agentes venham a se dispor antagonicamente" (p. 139).

Na seção final do livro, Santos examina, brevemente, a enormidade do desafio democrático, ao tentar o regime responder à aspiração de governos simultaneamente estáveis, inteligentes e inovadores, aspirações que freqüentemente se chocam umas com a outras. Como ele reconhece, "as instituições democráticas, ao revés de todas as anteriores, são especializadas em administrar fracassos, exceto um: o de impedir que os conflitos, econômicos e políticos atinjam o ponto crítico". Mas, mesmo sem atingir esse ponto, que os políticos procuram evitar, o sistema pode operar em nível subótimo social. Isso, observa, "enquanto não existe nenhum grupo específico para o qual os custos de tolerar frustrações sejam inferiores 
aos de estimular o acréscimo na taxa de incerteza com a chegada ao ponto crítico" (p. 150). A situação pode tornar-se um dilema do prisioneiro, no qual o conhecimento do desenlace só alimenta a velocidade com que os adversários se encaminham para o desastre, cada um com a esperança de que o desastre seja unilateral e a recompensa só por ele apropriada. Na verdade, alerta Santos, os beneficiários serão participantes estranhos às disputas, feitos árbitros finais de um conflito sem retorno. Mas, insiste, não são as instituições democráticas as responsáveis por sua própria instabilidade, "expostas que estão às devastadoras conseqüências das erráticas expressões da subjetividade humana" (p. 151). E conclui com esta defesa do regime popular: "O que desarranja um sistema político democrático é precisamente aquilo que o transcende, dificilmente o que o põe em funcionamento. Quanto mais natural a operação democrática, menos necessária se faz a sua governabilidade extrínseca" (idem).

Governabilidade e democracia natural é, sem dúvida, texto indispensável, de interesse não apenas para os estudiosos da política brasileira, mas também para quem quer que se preocupe com este tema central da ciência política, que são as condições de operação efetiva do regime democrático.

\section{Notas}

1 Seymour Martin Lipset, "Some social requisites of democracy: economic development and political legitimacy", American Political Science Review, 53 (1): 69-105, 1959.

2 Orlando de Carvalho, Ensaios de sociologia eleitoral, Belo Horizonte, Revista Brasileira de Estudos Políticos, 1958.

3 Presumimos que, ao lado de diferenciações de várias ordens, os eleitores sejam também, assim como os representantes, conforme nos indica o próprio Santos, "orientados por um conjunto de questões, normalmente cruciais, que dê origem a um escalograma de Guttman, com alto coeficiente de reproducibilidade [...]" (p. 156). Na presença de restrições legais, tipo cláusula de barreira, podem optar pela agremiação que, entre as viáveis, mais se aproximam de sua posição.

4 Dieter Nohlen chamou a atenção para tal fato após examinar as primeiras eleições alemãs reali- zadas sob a vigência da cláusula restritiva. Por exemplo, dados da eleição de 1994, que temos à mão, mostram que os votos partidários esterilizados pela aplicação da cláusula de barreira em 1994 foram da ordem de 3,4\% do total.

5 Observa, contudo, que Sartori cede, muitas vezes, no fascínio pelo número de partidos parlamentares, como que olvidado dessas variáveis cruciais.

6 O autor tem particular ojeriza a essa medida, conhecida como N. Defende que se use, em vez dela, a medida do número de partidos significativos, ou seja, os que entram no cálculo de F, em vários níveis de significação computacional, bem como o número de cadeiras desconsideradas no cálculo. Argumenta, persuasivamente, que, sobretudo se a diferença de tamanho entre governo e oposição for mínima, é preciso investigar o potencial de coalizão com partidos significativos a $1 \%$ e não a 3\%. Além disso, é preciso saber a inclinação ideológica dos partidos e a intensidade de suas preferências, algo que nenhuma medida estrutural sobre parlamentos é capaz de produzir (p. 127). Sobre o índice N (número efetivo de partidos), ele tem razão de mostrar o indevido deslocamento do adjetivo "efetivo", que, em vez de ligar-se ao número, significando portanto a característica do sistema partidário, passa a qualificar partido, levando assim a um conceito de confusa interpretação.

7 Wanderley Guilherme dos Santos, O cálculo do conflito, Belo Horizonte/Rio de Janeiro, Editora da UFMG/Iuperj, 2003.

\footnotetext{
ANTONIO OCTÁVIO CINTRA é doutor em Ciência Política pelo MIT, consultor legislativo da Câmara dos Deputados e lecionou ciência política na UFMG e na UnB (E-mail: antonio.cintra@camara.gov.br).
} 